\title{
Produtividade e Influências Intersetoriais das Telecomunicações nas Economias Mundiais
}

Productivity and Intersectoral Influences of Telecommunications in the World Economies

\author{
Matheus Lily Serrão Dilon ${ }^{a}$ \\ Admir Antonio Betarelli Junior ${ }^{\mathrm{b}}$ \\ Weslem Rodrigues Fariac \\ Rosa Livia Gonçalves Montenegro ${ }^{d}$
}

\begin{abstract}
Resumo: O objetivo desse estudo é analisar as variações da produtividade e as principais influências intersetoriais associadas ao setor de telecomunicações nas principais economias mundiais, como Alemanha, Brasil, China, Estados Unidos, França, Japão e Reino Unido. Para tanto, aplica-se as técnicas de campo de influência e produtividade total dos fatores sobre matrizes interregionais de insumo-produto entre 2004 e 2014. Os resultados conclusivos apontam que ganhos de produtividade do setor de telecomunicações e que ganhos de eficiência sobre o uso de seus serviços, por parte dos setores produtivos, podem levar a uma menor influência sobre telecomunicações.
\end{abstract}

Palavras-chave: Telecomunicações; Produtividade; Campo de Influência.

Classificação JEL: C67; L96; O57.

\begin{abstract}
The main aim of this paper is to analyze the changes in productivity and the main intersectoral influences associated with the telecommunications services in the main world economies, such as Germany, Brazil, China, the United States, France, Japan and the United Kingdom. To accommodate this task, we applied two techniques on interregional inputproduct matrices between 2004 and 2014: (i) total factor productivity and (ii) field techniques of influence. The main findings indicate that productivity and efficiency gains in the telecommunications sector can lead to less intersectoral influence on the type of service itself.
\end{abstract}

Keywords: Telecommunications; Productivity; Fields of Influence.

JEL Classification: C67; L96; O57.

\footnotetext{
${ }^{a}$ Graduado em Ciências Econômicas pela Universidade Federal de Juiz de Fora (UFJF).

E-mail: matheusdilon@hotmail.com.

${ }^{\text {b }}$ Professor da Faculdade de Economia e do Programa de Pós-Graduação em Economia (PPGE) da UFJF.

E-mail: admir.betarelli@ufjf.edu.br.

${ }^{c}$ Professor da Faculdade de Economia e do PPGE da UFJF. E-mail: weslem.faria@ufjf.edu.br.

${ }^{\text {d }}$ Professora da Faculdade de Economia e do PPGE da UFJF. E-mail: rosa.livia@ufjf.edu.br.
} 


\section{Introdução}

A partir de 1980, as telecomunicações sofreram um movimento de expansão por todo o mundo em meio a um aumento da demanda por seus serviços, influenciados pelo surgimento de novas tecnologias, como circuitos eletrônicos digitais e da rede mundial de computadores (internet) e, por mudanças estruturais de mercado. De 1980 até o início do século XXI, a quase totalidade das companhias do setor no mundo se encontrava privatizada ou passou a se deparar com outras empresas de capital privado em um momento de crescente liberalização comercial. Tal modelo deixou para trás o esquema de negócios monopolista estatal para operar em mercados com concorrência regulada por agentes públicos. A mudança para um ambiente competitivo com preços regulados das telecomunicações pode ter influenciado o rápido crescimento do setor e a oferta de melhores serviços Silva; Perobelli (2018).

Os serviços prestados pelas empresas de telecomunicações até a década de 1980 incluíam apenas telefonia e fax. Após as privatizações e demais avanços tecnológicos da década de 1980 até 2017, os serviços se diversificaram ainda mais, passando a incluir telefonia celular, internet, TV por assinatura e outros serviços especializados em comunicação. A partir de múltiplas plataformas e tecnologias, foi proporcionada rapidez e agilidade no envio e recebimento de áudio, dados, texto e vídeo em tempo real de e para praticamente qualquer lugar. A partir desses recursos, tornou-se possível encurtar as distâncias entre indivíduos (pessoas, empresas, organizações e governos), agilizar a realização de negócios e transações, estimular a abertura de novos empreendimentos por meio da criação de novos recursos e redução de custos, universalizar o acesso à informação, proporcionar maiores opções de entretenimento e conhecimento a partir de treinamentos e cursos com aulas ministradas à distância, dentre muitos outros benefícios e facilidades.

Em 2017, o mundo já havia vivido plenamente a chamada "sociedade da informação" por mais de duas décadas. Tal título fora dado como substituto ao então estado de "sociedade pós-industrial", ressaltando as transformações organizacionais, técnicas e econômicas. Assim, o mundo passou a ver a informação tomar lugar semelhante à da energia. Em outras palavras, como um importante insumo da civilização diante dos avanços e difusão das tecnologias de microeletrônica e telecomunicações Werthein (2000). Vivenciando os primeiros anos da Quarta Revolução Industrial (Indústria 4.0), em um mundo plenamente globalizado, comunicar-se de maneira eficiente nunca foi tão imprescindível. Inclusive, grande parte dos empreendimentos, se não a sua totalidade, necessita da presença de uma infraestrutura que viabilize tais recursos. Ainda assim, notase a existência de muitos gargalos a serem superados, especialmente no que se concerne à universalização do seu acesso International Telecommunication Union (2017). Seguindo a literatura econômica, alguns autores sugerem que os setores de infraestrutura básica, como energia, saneamento, transporte e telecomunicações são considerados setores chaves para manutenção do crescimento e desenvolvimento das economias Hirschman; Schlaeffer (1960 e Perroux (1967). 
Os trabalhos que versam sobre o tema do presente artigo comumente comparam as telecomunicações entre países pela ótica do investimento - e.g. Aschauer 1989) e Cronin et al. 1993) - ou a partir de dados da densidade de telefones - fixo e celular - e conexão de banda larga - fixa e móvel - e.g. Lam e Shiu 2010), Sridhar e Sridhar 2009). Ainda que comprovem a relação positiva entre a expansão do setor com o crescimento, desenvolvimento e aumento da produtividade econômica, estudos aplicados apontam pouco destaque sobre a evolução da produtividade do próprio setor com o passar do tempo. Assim como, salienta-se a intensidade das interações com os demais setores produtivos, a maneira e a magnitude do impacto com as telecomunicações no mundo.

Visando preencher essa lacuna, o presente trabalho escolheu estudar as oito maiores economias produtoras de telecomunicações, a partir da matriz de insumo-produto interregional mundial da base de dados World Input-Output Database (WIOD) de 2014, ano mais recente disponível. Na matriz, vê-se o Brasil na oitava posição ao lado de outros seis países (Alemanha, China, Estados Unidos, França, Japão e Reino Unido) e o Resto do Mundo. Uma vez que a matriz mostra que o setor em estudo interage comercialmente com todos os demais setores da economia, o principal objetivo é captar e analisar as principais influências e interdependências desse setor com ele próprio e com todos os demais em cada uma das economias selecionadas. Além disso, será possível avaliar e comparar as mudanças de produtividade do setor em cada uma das economias dentro do período de uma década, utilizando para isso as matrizes dos anos 2004 e 2014. É nesse mote de pesquisa que se busca responder: Quais seriam as principais mudanças de produtividade do setor de telecomunicações entre os anos de 2004 e 2014 e quais as interdependências entre esse setor e os demais setores produtivos nas oito maiores economias produtoras de telecomunicações?

Para alcançar os resultados, o artigo empregou duas técnicas. A primeira foi a de produtividade total de fatores, que permitiu a análise e comparação da evolução da eficiência e produtividade do setor nas economias ao longo desses dez anos. A segunda técnica foi a de campo de influência, que buscou verificar as principais interações de compra e venda e interdependência do setor de telecomunicações com ele próprio e os demais setores nas economias selecionadas. Com os resultados, espera-se encontrar maiores interações das telecomunicações com os setores ligados à sua cadeia produtiva, em especial com os setores fabricantes de equipamentos eletrônicos e de energia, assim como com as atividades que utilizam intensamente tecnologias da informação e comunicação no seu processo produtivo, como os relacionados ao setor de serviços. Já com relação à influência por parte dos seus principais demandantes, almeja-se visualizar uma queda dessa interação nas localidades onde as telecomunicações apresentem ganhos de produtividade no período de dez anos considerado.

De posse dos resultados, ou seja, conhecendo os principais setores demandantes das telecomunicações e os efeitos decorrentes de um aumento de sua produtividade, tanto o setor público quanto o privado poderão tirar proveitos dessa pesquisa. O setor público, por exemplo, poderá saber quais atividades econômicas serão influenciadas indiretamente mediante um estímulo - e.g. redução de alíquotas de impostos - dado ao setor de 
telecomunicações. Ademais, as companhias do próprio setor de telecomunicações, basicamente representadas por empresas de capital privado, ao saberem os nichos produtivos que mais demandam seus produtos e serviços, mediante incentivos governamentais direcionados à expansão ou deslocamento regional daqueles, poderão ser capazes de otimizar suas operações e recursos.

Além desta seção introdutória, este artigo subdivide-se em mais quatro seções. A segunda seção apresenta uma breve descrição das telecomunicações e o referencial empírico sobre o setor. Em sequência, a terceira seção discorre sobre as técnicas e a base de dados. A quarta seção fornece a análise dos resultados. Por fim, a quinta e última seção apresentam as considerações finais.

\section{O Setor em Estudo nas Economias Mundiais}

À medida que as tecnologias de comunicação avançaram, os meios de comunicação mudaram, impactando tanto na forma da sociedade se organizar como na própria economia. Até o final da década de 1970, a definição de telecomunicação era simples: prestar serviços de telégrafo ou telefonia a fim de viabilizar comunicação à distância por sinais ou voz. No entanto, a partir de 1980, o mercado das telecomunicações se transformou. A primeira mudança adveio de políticas de reestruturação organizacional das empresas de telecomunicações. Esse processo consistia em um movimento global de liberalização comercial e privatização do setor. Os principais problemas enfrentados com relação ao setor envolviam: longa espera para instalação dos serviços, baixa qualidade dos mesmos e baixa produtividade do setor como um todo Ros; Banerjee (2000).

Na busca da correção desses gargalos, a abertura de mercado ao capital privado se iniciou no Reino Unido no ano de 1980, quando o governo privatizou a British Telecom. Até 1985, menos de 2\% das companhias de telecomunicações em 167 países eram privatizadas. As privatizações, entretanto, aceleraram na década de 1990. Até o final de 1998, a proporção de empresas de telecomunicações privatizadas subiu para $42 \%$. Como resultado desse movimento, em muitos países, a competição na oferta e qualidade de serviços cresceram, passando o Estado a ser responsável apenas pela regulação desse setor, intermediando os interesses dos investidores e usuários Li; Xu (2002).

Outra transformação no setor foi atribuída a um movimento de integração das telecomunicações à informática, decorrente da expansão da internet. Essas mudanças levaram a uma aceleração do crescimento do setor e ao surgimento de novas tecnologias, aplicações e serviços de telecomunicações. Dessa forma, a infraestrutura de telecomunicações passou a permitir a oferta não apenas dos serviços tradicionais, como telefonia e fax, como também a prestação de múltiplos serviços de telecomunicação e de valor adicionado ${ }^{1}$ a partir da mesma rede. Inclusive, a integração à internet acarretou em um aumento exponencial da quantidade de informações compartilhadas, demandando um

\footnotetext{
${ }^{1}$ Serviços de valor adicionado são atividades que aproveitam o meio físico das telecomunicações oferecendo novas utilidades relacionadas ao acesso, armazenamento, apresentação, movimentação ou recuperação de informações, porém não são considerados telecomunicações.
} 
aumento da capacidade das redes de telecomunicação de levar conteúdos e mídias a múltiplos dispositivos - celulares, tablets, laptops, desktops, televisores, e muitos outros - a partir das mais variadas tecnologias - Redes cabeadas (Cable Modem ${ }^{2}$, Fibra, $\mathrm{xDSL}^{3}$ e outras), Redes Sem Fio (Wi-Fi, $4 \mathrm{G}^{4}$ e outras) e Satélite. Esses fatores levaram à formação de uma cadeia produtiva extensa e ramificada.

A prestação de telecomunicações pode ser dividida em três camadas. A camada física - abrange a fabricação e administração das partes mecânicas, elétricas, óticas, para o gerenciamento de conexões de rede de comunicação -; a camada de transporte corresponde aos serviços de transferência e manipulação dos dados entre as redes a fim de garantir que o serviço de telecomunicação contratado chegue adequadamente ao usuário final -; e a camada de aplicações - responsável por prover serviços de valor adicionado especializados em facilitar a comunicação aos usuários em diferentes plataformas Council (2006).

Ainda que a primeira camada se constitua de empresas cujas linhas de montagem forneçam os equipamentos indispensáveis ao funcionamento do setor, como fabricantes de chips e de placas eletrônicas voltados aos produtos de telecomunicação (e.g. Intel, Qualcomm e Broadcom) e de equipamentos de rede (e.g. Siemens, Huawei e Alcatel); e a terceira facilite a usabilidade das redes de telecomunicações, a partir da disponibilização de navegação web, e-mails e comunicação em tempo real (e.g. Microsoft - Skype e Facebook - WhatsApp; dentre outros); é importante lembrar que ambas as atividades não são consideradas pela International Standard Industrial Classification of All Economic Activities (ISIC) típicas de telecomunicações.

Segundo a $4^{a}$ Revisão da ISIC, fonte do critério de caracterização setorial das MIPs oriundas da base de dados WIOD, telecomunicações faz parte dos serviços de "Informação e Comunicação". Assim, tal setor inclui a viabilização de transmissão e recebimento de conteúdo e mídia - voz, dados, áudio e vídeo - sem estar envolvido em sua criação, excluindo os casos nos quais operadoras de TV por assinatura produzem conteúdo. Enquadram-se também como serviços de telecomunicações a revenda de serviços como, por exemplo, compra e revenda de capacidade de rede ainda que nenhum serviço adicional seja prestado (e.g. venda de capacidade pelas grandes operadoras para provedores locais) United Nations (2008).

O Relatório Global de Competitividade 2016-2017, feito pelo Fórum Econômico Mundial, destaca a chegada da Quarta Revolução Industrial - ou "Indústria 4.0". Baseada em plataformas digitais por meio de uma maior integração às Tecnologias de Informação e Telecomunicações (TICs), essa nova revolução não se define pela chegada de uma nova tecnologia, mas pela migração de toda informação e produção para sistemas digitais interligados. Substituir a forma de automação industrial requer integração e comunicação em tempo real de todas as etapas do processo produtivo e a telecomunicação é a atividade

\footnotetext{
${ }^{2}$ Tecnologia de transmissão de dados digitais via cabo coaxial.

${ }^{3}$ Família de tecnologias que são usadas para transmitir dados digitais sobre linhas telefônicas.

${ }^{4}$ Tecnologia de transmissão de dados em alta velocidade a partir de redes de celular.
} 
fornecedora do meio - infraestrutura - e serviços responsáveis por tornar isso realidade, ela se torna indispensável à existência dessa nova era da economia.

As atividades do setor de telecomunicação apresentaram crescimento sem precedentes desde os anos 2000, especialmente em razão da difusão da telefonia móvel, fazendo desse um dos serviços mais utilizadas em todo mundo. Inclusive, em muitos países há mais pessoas com uma linha de celular do que com uma conta no banco, acesso à eletricidade ou mesmo água potável. Até o final de 2016, as telecomunicações ligavam sete bilhões de pessoas - 95\% da população mundial - à rede de telefonia celular World Bank (2016). No Gráfico 1 é possível acompanhar a evolução do número de linhas celular para cada 100 habitantes. Até 2020, é esperado que mais 860 milhões de usuários se juntem à rede mundial de telefonia móvel, representando uma participação de $75 \%$ da população global - ou 5,7 bilhões de pessoas. Com os mercados desenvolvidos se aproximando da saturação quanto à penetração desse serviço, estima-se que 9 de cada 10 futuros novos assinantes serão de regiões em desenvolvimento GSMA Intelligence (2017).

\section{Gráfico 1: Número de Linhas Móveis por 100 Habitantes}

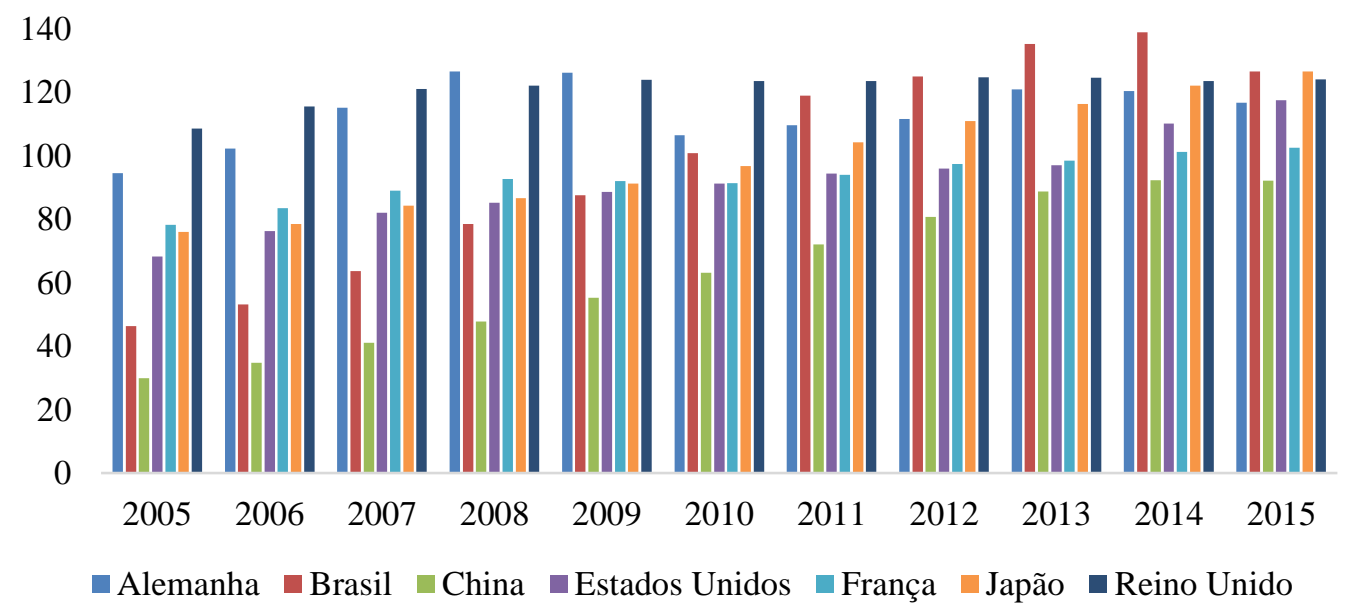

Fonte: World Bank (2016).

As pessoas não se conectam à internet, na verdade, elas estão na maior parte do tempo "naturalmente" online. O número de usuários de internet mais que triplicou em uma década - de 1 bilhão, no ano de 2005 para 3,2 bilhões, no final do ano de 2015 . Isso significa que em qualquer lugar, pessoas, negócios e governos estão se tornando cada vez mais conectados World Bank (2016). Não só a banda larga fixa, mas principalmente a banda larga móvel tornou-se o serviço responsável pela massificação da internet. Agregado a planos e utilizando da mesma rede de telefonia celular, 84\% da população mundial está apta, em termos tecnológicos, de adquirir planos com internet móvel em alta velocidade - mediante tecnologias 3G ou 4G. Ainda assim, 3,9 bilhões de pessoas - 
$53 \%$ da população do globo - continuam fora da internet - offline International Telecommunication Union (2017). O Gráfico 2 apresenta o percentual de pessoas online e offline em cada continente.

\section{Gráfico 2: Distribuição (\%) Continental de Pessoas Online e Off-line}

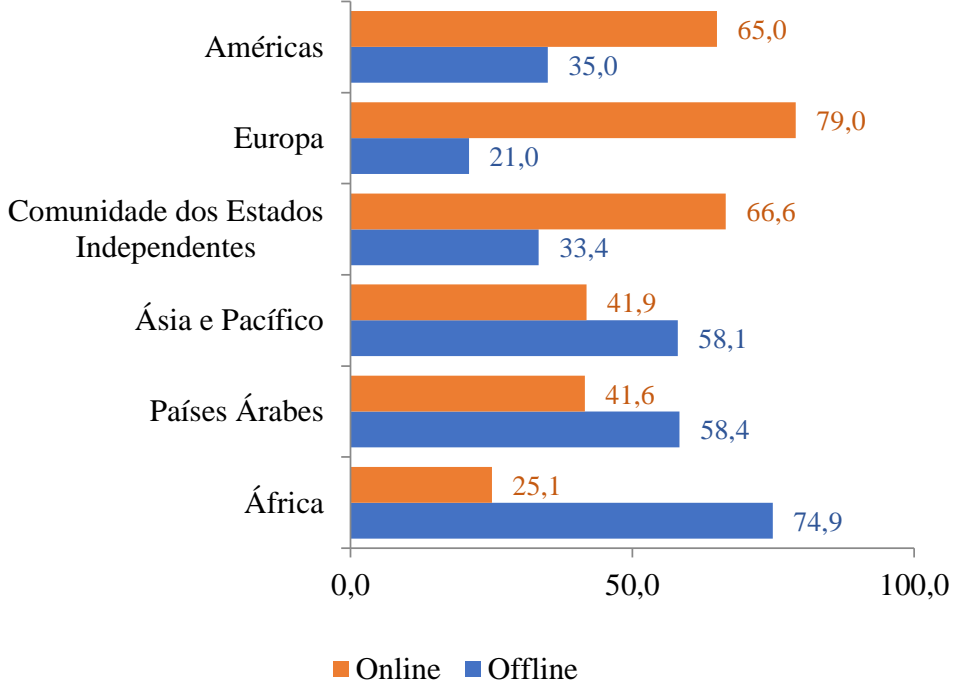

Fonte: International Telecommunication Union (2017).

A maior parcela da responsabilidade deve-se aos altos custos relativos aos serviços de internet fixa e móvel. No entanto, segundo o documento Measuring the Information Society Report 2017), esse cenário vem mudando e os preços diminuem com o passar do tempo. De maneira geral, o preço de uma conexão de banda larga fixa caiu de US\$ 80/mês em 2008 para US\$ 25/mês em 2015; e os preços de uma conexão móvel passaram de US $\$ 21 /$ mês em 2008 para US $\$ 13 /$ mês. Outro item que compõe a cesta de produtos do setor de telecomunicações é o serviço de TV por assinatura. Entre os anos de 2010 a 2014, o mercado global de TV pago apresentou um crescimento médio da base de assinantes de 4\% a.a., chegando ao final desse período com mais de 900 milhões de assinantes e um aumento de $19 \%$ na receita, passando de US\$ 216 para US $\$ 257$ bilhões ABI RESEARCH (2017). Entre os anos de 2010 a 2014, observou-se crescimento na receita da TV paga em todas as regiões no mundo. No entanto, devido ao surgimento de novos serviços (e.g Netflix, Amazon Prime, YouTube) também capazes de levar o entretenimento em forma de vídeo diretamente a qualquer dispositivo conectado à internet - celular, tablet, smartphone, smartTVs e outros - a concorrência com o serviço de TV por assinatura tem aumentado.

A literatura aplicada tem utilizado diferentes abordagens metodológicas para evidenciar o papel crescente do setor de telecomunicações em uma economia ou um conjunto de regiões econômicas com distintos estágios de desenvolvimento. Logo após o 
período pós-reforma do setor, os estudos aplicados abordaram majoritariamente questões como: crescimento econômico, investimentos e de produtividade, associados direta ou indiretamente com a expansão da infraestrutura ou dos serviços de telecomunicações no mundo. Usualmente, as abordagens metodológicas utilizadas são modelos econométricos, análise de envoltória de dados (DEA) e modelos de insumo-produto. $\mathrm{Na}$ abordagem econométrica, algumas pesquisas aplicadas geralmente comparam telecomunicações entre países sobre a perspectiva do investimento - por exemplo, Aschauer 1989) e Cronin et al. 1993) - ou por meio de dados de densidade de telefone - fixo e móvel - e conexão de banda larga (fixa e móvel), como, por exemplo, Sridhar e Sridhar 2009).

Outros estudos procuraram avaliar a importância das telecomunicações no nível de produtividade de diferentes países, principalmente após o crescimento das telecomunicações móveis. Por exemplo, Lam e Shiu 2010) avaliaram o cenário do setor de telecomunicações em mais de 100 países de todas as regiões do mundo após o ano de 1998, período de grandes reformas no setor (novas tecnologias, aberturas de mercado e privatizações). De maneira mais estrita, Niebel 2018) analisou os efeitos da produtividade das tecnologias de informação e comunicação (TIC) sobre o crescimento econômico de países em desenvolvimento, emergentes e desenvolvidos. Jung, Na e Yoon 2013) testaram se a convergência tecnológica tem sido a principal força motriz do recente aumento de produtividade na Coreia do Sul, levando em conta o efeito das TICs sobre a PTF. Essa pesquisa mostrou que as operadoras de telecomunicações da Ásia-Pacífico tinham melhor eficiência de produtividade do que as da Europa e América, mas as diferenças não eram significativas. Concluiu-se que a concorrência no mercado global de telecomunicações continuaria ligada à maior eficiência da produtividade.

Entretanto, esses estudos aplicados com DEA não levaram em conta a interação setorial do setor de telecomunicações em um sistema produtivo, cujo aspecto é mais bem explorado a partir dos canais diretos e indiretos dos elos de produção e consumo em um modelo de insumo-produto. Por essa razão, pesquisas aplicadas recorreram aos modelos de insumo-produto para avaliar a importância relativa do setor de telecomunicações mediante ao uso de análises de coeficientes ou de mudanças estruturais ocorridas no setor ao longo de um período selecionado para um conjunto de países. Nessa variante, Rohman 2013) estudou a importância dos setores de TIC para o desempenho econômico nas economias europeias, comparando tal desempenho em dois intervalos temporais (2000-2005; 19952000). Rohman e Bohlin 2014) avaliaram o papel das telecomunicações na Indonésia entre os anos de 1975 e 2008, comparando as mudanças estruturais ocorridas no setor de telecomunicações entre as épocas pré e pós-celular. O estudo de Hong, Byun e Kim 2016) aplicou uma decomposição estrutural de insumo-produto para analisar a atividade de TIC na Coreia do Sul entre os anos de 1995 e 2009, em termos de mudanças estruturais e fatores de crescimento do setor. Inklaar e Timmer 2007) realizaram uma análise exploratória sobre medidas setoriais com o objetivo de comparar as produtividades setoriais entre sete economias de alta renda, destacando as mudanças no setor de TIC. Os seus resultados indicaram que os níveis de produtividade eram relativamente semelhantes nos países europeus e anglo-saxônicos, mas havia diferenças nas estruturas de produção. 
Em geral, mesmo com diferentes abordagens metodológicas, os trabalhos supracitados evidenciam uma importância gradual do setor de telecomunicações para as economias mundiais, sejam elas desenvolvidas ou em desenvolvimento. Não obstante, não é consensual os ganhos de produtividade do setor de telecomunicações após o período das reformas, marcado pelo rápido crescimento da oferta do setor no mundo. Este artigo acompanha essa categoria de estudos aplicados com modelos de insumo-produto, a fim de avaliar a eficiência e a produtividade dos fatores primários nas telecomunicações em sistemas econômicos inter-regionais. Essa avaliação fornecerá os fatores que levaram às flutuações da PTF nas principais economias mundiais e fornecedoras dos serviços de telecomunicações. Espera-se que os resultados possam complementar as análises feitas especialmente por Lam e Shiu 2010) e Chakraborty e Nandi 2011), ao apontar se as variações de PTF seriam relativamente maiores em países em desenvolvimento.

\section{Metodologia}

O modelo de insumo-produto representa uma forma de retratar a imagem de uma economia em um determinado ano e detalha todos os fluxos de compra e venda de cada um dos setores produtivos de uma economia. A estrutura do modelo acompanha a de equilíbrio geral e, além disso, inerente a essa metodologia estão hipóteses como oferta perfeita elástica de insumos, tecnologia de retornos constantes de produção (Leontief) e demanda final exógena, bem como os preços são rígidos Miller; Blair (2009). Um modelo interregional de insumo-produto (IR-IP) reconhece cinco componentes de demanda final, sendo o consumo das famílias, o consumo do governo, as exportações, os investimentos (formação bruta de capital fixo) e variação de estoques. O modelo interregional de insumoproduto pode ser demonstrado a partir dos fluxos intersetoriais e interregionais de dois setores ( $\mathrm{i}$ e j) entre duas regiões. O sistema interregional de Leontief pode ser observado da seguinte forma:

$$
\mathbf{x}=\mathbf{Z}+\mathbf{f}
$$

onde: $\mathbf{x}^{\prime}=\left[\begin{array}{ll}\mathbf{x}^{\mathrm{L}} & \mathbf{x}^{\mathrm{M}}\end{array}\right]$ é o vetor de produção setorial; $\mathbf{f}^{\prime}=\left[\begin{array}{ll}\mathbf{f}^{L} & \mathbf{f}^{M}\end{array}\right]$ corresponde à matriz de demanda final, ambas as matrizes particionadas por regiões $\mathrm{L}$ e $\mathrm{M}$; e $\mathbf{Z}^{\prime}=\left[\begin{array}{ll}\mathrm{Z}^{\mathrm{LL}} & \mathrm{Z}^{\mathrm{LM}} \\ \mathrm{Z}^{\mathrm{ML}} & \mathrm{Z}^{\mathrm{MM}}\end{array}\right]$ refere-se à matriz de consumo intermediário, de maneira que as submatrizes $\mathrm{Z}^{\mathrm{ML}} \mathrm{e} \mathrm{Z}^{\mathrm{LM}}$ representam os fluxos interregionais, ao passo que as submatrizes $\mathrm{Z}^{\mathrm{LL}}$ e $\mathrm{Z}^{\mathrm{MM}}$ referem-se aos fluxos intrarregionais. Assim, a matriz de coeficientes tecnológicos é definida por $\mathbf{A}=$ $\mathbf{Z}(\hat{\mathbf{x}})^{-1}$. Pode-se resolver a equação (1) como:

$$
\mathbf{x}=\mathbf{B f}
$$

em que $\mathbf{B}=(\mathbf{I}-\mathbf{A})^{-1}$ é a matriz Inversa de Leontief e $\mathbf{I}$ representa a matriz identidade. 


\subsection{Campo de Influência}

Desenvolvida por Sonis e Hewings 1989, 1999), a técnica de campo de influência é capaz de mostrar como se distribuem as mudanças dos coeficientes diretos dentro da economia. Dessa forma, permite-se identificar, entre os variados setores econômicos, quais seriam os mais importantes dentro do processo produtivo. Em outras palavras, a determinação dos setores que apresentam um maior poder de influência sobre os demais, ou melhor, quais coeficientes que, alterados, teriam um maior impacto no sistema como um todo. Dada um incremento ou perturbação ou de um determinado elemento da matriz que $\mathbf{E}=\left\{\varepsilon_{i j}\right\}$ no coeficiente técnico qualquer $\mathbf{A}=\left\{a_{i j}\right\}$, define-se a solução do sistema como:

$$
\boldsymbol{B}(\varepsilon)=(\boldsymbol{I}-\boldsymbol{A}-\boldsymbol{E})^{-1}=\left[b_{i j}(\varepsilon)\right]
$$

A variação $\varepsilon_{i j}$ é pequena e ocorre em apenas um único coeficiente técnico, conforme a seguinte lógica matemática:

$$
\varepsilon_{i j}=\left\{\begin{array}{l}
\varepsilon ; i=i_{1}, j=j_{1} \\
0 ; i \neq i_{1} ; j \neq j_{1}
\end{array}\right.
$$

Dessa forma, existe uma aproximação do campo de influência pela seguinte expressão:

$$
\boldsymbol{F}\left(\varepsilon_{i j}\right) \cong \frac{\left[\boldsymbol{B}\left(\varepsilon_{i j}\right)-\boldsymbol{B}\right]}{\varepsilon_{i j}}
$$

onde $\boldsymbol{F}\left(\varepsilon_{i j}\right)$ representa a matriz de dimensão $\times$ nn do campo de influência da perturbação no coeficiente direto $a_{i j}$. Assim, cada elemento daquela matriz é associado a perturbação correspondente no coeficiente direto. Para determinar os coeficientes que possuem os maiores campos de influência, utiliza-se um valor $S_{i j}$, que é associado a cada matriz $\boldsymbol{F}\left(\varepsilon_{i j}\right)$, da seguinte forma:

$$
S_{i j}=\sum_{k=1}^{n} \sum_{I=1}^{n}\left[f_{K I}\left(\varepsilon_{i j}\right)\right]^{2}
$$

Deste valor associado, $S_{i j}$, pode ser construída uma hierarquia dos coeficientes diretos baseados no seu campo de influência. Assim, setores mais sensíveis às perturbações serão aqueles cujos coeficientes diretos associados aos maiores valores de $S_{i j}$, isto é, aqueles que tiverem os maiores campos de influência no sistema. 


\subsection{Produtividade Total de Fatores (PTF)}

Uma das variáveis capazes de afetar o crescimento da economia é a sua taxa de produtividade. A produtividade total dos fatores (PTF) é definida como o crescimento total do produto não atribuído ao aumento dos insumos. Conforme o método de Miller e Blair 2009), pode-se definir o produto $\left(x_{j}\right)$ como:

$$
x_{j}=\sum_{i=2}^{n} a_{i j} x_{j}+v_{j} x_{j}=\left(\sum_{i=1}^{n} a_{i j}+v_{j}\right) x_{j}
$$

onde $a_{i j}$ é o coeficiente técnico de produção, tal que $a_{i j} x_{j}$ denota o uso do insumo $i$ na produção do setor $j$; e $v_{j}$ representa o coeficiente do valor adicionado $\left(v a_{j}\right)$, definido por $v a_{j} / x_{j}$. Utiliza-se o método da diferenciação na equação (7) a fim de obter taxa de variação:

$$
d x_{j}=d\left[\left(\sum_{i=1}^{n} a_{i j}+v_{j}\right) x_{j}\right]=\left(\left(\sum_{i=1}^{n} a_{i j}+v_{j}\right) d x_{j}\right)+\left(\sum_{i=1}^{n} d a_{i j}+d v_{j}\right) x_{j}
$$

Desse modo, a taxa de crescimento da PTF, $\tau_{j}$, passa a ser definida pela variação da produção do setor no período, ou seja:

$$
\tau_{j}=-\left(\sum_{i=1}^{n} a_{i j}+v_{j}\right) d x_{j}
$$

Se o valor for negativo para $\tau_{j}$, verifica-se um declínio da produtividade. Ademais, a partir das equações (8) e (9) é possível expressá-las em forma de diferença-finita para dois períodos sequenciais, $\tau_{j}=[0,1]$, tal que $d x_{j} \cong \Delta x_{j}=x_{j}^{1}-x_{j}^{0}, d a_{j} \cong \Delta a_{j}=a_{j}^{1}-a_{j}^{0} \mathrm{e}$, $d v_{j} \cong \Delta v_{j}=v_{j}^{1}-v_{j}^{0}$ :

$$
x_{j}^{1}-x_{j}^{0}=\left[\left(\sum_{i=1}^{n} a_{i j}+v_{j}\right) \Delta x_{j}\right]+\left(\sum_{i=1}^{n} \Delta a_{i j}+\Delta v_{j}\right) x_{j}
$$

Portanto, a forma de diferença-finita da equação (9) torna-se:

$$
\boldsymbol{\tau}=-\left[\left(\boldsymbol{i}^{\prime} \Delta \boldsymbol{A}\right)^{\prime}+\Delta \boldsymbol{v}\right]=-\left[\sum_{i=1}^{n} \Delta a_{i j}+\Delta v_{j}\right]
$$

em que $\boldsymbol{i}$ denota um vetor coluna de 1. A partir desse ponto, pode-se decompor a equação (11) da PTF em duas partes: uma de "eficiência", $\left(\boldsymbol{i}^{\prime} \boldsymbol{\Delta} \boldsymbol{A}\right)^{\prime}$, e outra dos fatores de produção, $\Delta \boldsymbol{v}$. Nesse sentido, torna-se possível distinguir a parte da mudança do produto atribuída aos ganhos de eficiência pelo uso dos insumos intermediários (tecnológicos) e a parte que pode ser atribuída aos fatores de produção. Por conveniência, e para facilitar a interpretação dos resultados, as variações da equação (11) serão apresentadas na forma de crescimento acumulado, pois a forma original da equação (11) representa variações entre os coeficientes estruturais de produção. 


\subsection{Base de Dados}

A matriz interregional de insumo-produto utilizada nesse trabalho origina-se do banco de dados da fonte de World Input-Output Database (WIOD), conforme apresentado por Dietzenbacher et al. 2013). A matriz original dessa base de dados, na versão lançada no ano de 2016, apresenta informações sobre o valor adicionado de 56 setores da economia (em milhões de dólares) para 43 países - 28 desses europeus e 15 de outras regiões - e o Resto do Mundo, entre os anos de 2004 a 2014. Essa versão acompanha a nova referência do sistema de contas nacionais do ano de 2008 United Nations (2008) e discrimina explicitamente o setor de telecomunicações. As matrizes da WIOD são fornecidas a preços correntes e a preços constantes do ano anterior, no qual, de acordo com Arto e Dietzenbacher 2014), são adequadas para medir as mudanças de tecnologia ano a ano.

Para este estudo, as matrizes originais foram redimensionadas para reconhecer a seguinte estrutura regional: Alemanha (DEU), Brasil (BRA), China (CHN), Estados Unidos (USA), França (FRA), Japão (JPN), Reino Unido (GBR) e Resto do Mundo (RoW) - uma agregação regional das demais regiões internacionais reconhecidas nas matrizes da WIOD. O critério de seleção levou em consideração as oito maiores economias produtoras de telecomunicações no ano de 2014. Cada região econômica apresenta características setoriais específicas, interdependências inter-regionais distintas, bem como de territorialidade, que influenciam as relações estruturais de compra e venda com o setor de telecomunicações. Além da agregação regional, fez-se também uma agregação setorial, agrupando os 56 setores originais em um total de 14 atividades correspondentes. Ambas as escolhas foram feitas de modo a adequar a estrutura setorial aos objetivos do trabalho, sem prejuízo de detalhamentos.

\section{Resultados}

A produção real do setor de telecomunicações no mundo cresceu $45,6 \%$ entre os anos de 2004 e 2014, uma média anual de 3,83\%, conforme os dados da WIOD. Essa expansão se traduziu em um aumento da participação do setor em relação à produção mundial, atingindo 2,29\%, no ano de 2014, o que representou um incremento de 0,13 p.p. (pontos percentuais) nos últimos 10 anos. A expansão dos serviços de telecomunicações foi maior que o aumento da oferta de outros setores produtivos no período. Observa-se, portanto, uma tendência global de crescimento acelerado do setor, a que se deve às grandes reformas realizadas nos anos de 1990, i.e. novas tecnologias, aberturas de mercado e privatizações, bem como à expansão da telefonia móvel nos anos 2000, tornando-o um dos serviços mais utilizados no mundo Heber; Fischer (1997). Até o final do ano de 2016, o setor vinculava sete bilhões de pessoas - 95\% da população mundial - à rede de telefonia móvel World Bank (2016 e World Bank Group (2016). No período contemporâneo, as tecnologias 4.0 digitais se adaptaram às necessidades das indústrias de manufatura (um novo estágio industrial), oferecendo padrões como fabricação com smart (inteligentes), 
produtos smarts, cadeia de suprimentos smart e trabalho smart, internet, serviços em nuvem, big data e respectivas análises Frank et al. (2019).

As sete maiores regiões produtoras de telecomunicação representaram, juntas, $61,55 \%$ da oferta mundial deste tipo de serviço em 2014 (Tabela 1). Houve uma redução de 3,43 p.p. em relação ao ano de 2000, apesar de todas as regiões apresentarem crescimento anual da produção do setor. Dessa maneira, o Resto do Mundo (RoW) ganhou essa participação relativa na produção do setor (3,43 p.p.), alcançando $38,45 \%$ no ano de 2014. O crescimento médio anual do Resto do Mundo foi expressivo (4,8\%), mas inferior em relação à economia chinesa $(7,45 \%)$ e francesa $(5,49 \%)$. De todo modo, os dados revelam um movimento de expansão da produção desses serviços para os demais países do mundo ou uma desconcentração regional da oferta desse tipo de serviços. Essa descentralização ocorreu em meio aos avanços tecnológicos, como novas tecnologias sem fio, capazes de levar infraestrutura e serviços a preços mais acessíveis e distantes dos grandes centros produtores, difundindo os serviços em todo o mundo. Os países desenvolvidos e em desenvolvimento têm direcionado suas políticas de investimento para expansão e modernização do setor em território nacional Datta; Mbarika (2006 e Koszerek et al. (2007 e Pradhan et al. (2017). Houve também um movimento de reestruturação global do setor, incentivado pelos avanços e difusão de microeletrônica e tecnologias da informação Werthein (2000). Ao final do ano de 2014, 55\% de todas as conexões em banda larga sem fio se localizavam em países em desenvolvimento, em contraste com apenas 20\%, no ano de 2008 World Bank Group (2016).

Tabela 1: Oferta Real dos Serviços de Telecomunicações Regionais

\begin{tabular}{|c|c|c|c|c|c|c|c|c|}
\hline \multirow{2}{*}{ Regiões } & \multicolumn{3}{|c|}{$\begin{array}{c}\text { Part. (\%) } \\
\text { mundial }\end{array}$} & \multicolumn{3}{|c|}{$\begin{array}{c}\text { Part. (\%) } \\
\text { nacional }\end{array}$} & \multicolumn{2}{|c|}{$\begin{array}{c}\text { Crescimento } \\
(2004-2014) \\
\end{array}$} \\
\hline & 2004 & 2014 & $\begin{array}{l}\text { Var. } \\
\text { p.p. }\end{array}$ & 2004 & 2014 & $\begin{array}{l}\text { Var. } \\
\text { p.p. }\end{array}$ & anual & total \\
\hline Brasil (BRA) & 1,8 & 1,4 & $-0,4$ & 2,2 & 1,7 & $-0,5$ & 1,3 & 14,2 \\
\hline China (CHN) & 4,8 & 6,7 & 1,9 & 1,4 & 0,9 & $-0,5$ & 7,4 & 105,1 \\
\hline Alemanha (DEU) & 4,8 & 3,9 & $-0,8$ & 2,0 & 2,1 & 0,1 & 1,9 & 20,6 \\
\hline França (FRA) & 3,5 & 4,1 & 0,6 & 2,0 & 3,2 & 1,1 & 5,5 & 70,6 \\
\hline Reino Unido (GBR) & 5,1 & 4,4 & $-0,7$ & 2,5 & 2,6 & 0,1 & 2,4 & 26,4 \\
\hline Japão (JPN) & 12,4 & 9,7 & $-2,7$ & 2,1 & 2,4 & 0,3 & 1,3 & 13,5 \\
\hline Estados Unidos (USA) & 32,6 & 31,3 & $-1,3$ & 2,5 & 3,1 & 0,6 & 3,4 & 39,6 \\
\hline Restante do Mundo (RoW) & 35,0 & 38,4 & 3,4 & 2,1 & 2,4 & 0,3 & 4,8 & 59,9 \\
\hline
\end{tabular}

Fonte: Matrizes anuais da WIOD.

A economia chinesa $(\mathrm{CHN})$ obteve o maior salto de participação na produção mundial de telecomunicação entre as sete regiões produtoras. Entre os anos de 2004 e 2014, a produção das telecomunicações chinesas teve uma variação positiva de 1,95 p.p. sobre a parcela na produção mundial de telecomunicações, atingindo $6,72 \%$ no final do período. Essa mudança se deve pelo expressivo crescimento anual de 7,45\%, praticamente dobrando o nível da produção em 10 anos. Como destacaram Chakraborty e Nandi 2011) e Yu et al. 
2008), essa trajetória ascendente e significativa estaria associada com as reformas internas que modificaram as configurações do mercado de telecomunicações chinês e dos investimentos na respectiva infraestrutura realizados na década de 1990.

Não obstante, dentro da economia chinesa a atividade de telecomunicações perdeu participação relativa, cuja parcela reduziu em 0,54 p.p., o que representou $0,89 \%$ da produção nacional no ano de 2014. Assim, embora o crescimento das telecomunicações na China tenha sido proeminente dentre as sete maiores produtoras regionais no mundo, essa expansão foi inferior se comparada ao crescimento de outras produções setoriais na própria economia. Desde os anos de 1990, a China implementou um conjunto de medidas para reformular o setor, incluindo a criação de novos concorrentes, a privatização e a reestruturação organizacional. O ponto de inflexão foi quando o país entrou na Organização Mundial do Comércio (OMC) no ano de 2001. A partir desse período, a economia passou a receber e atrair investimentos estrangeiros na operação de serviços de telecomunicações. Evidências empíricas indicam uma relação positiva entre Tecnologias de Informação e Telecomunicações (TIC), investimento estrangeiro direto (IED) e crescimento econômico incorporando comércio e globalização para as economias do BRICS no período 2000-2014, com especial atenção para a China Latif et al. (2018). Segundo Lam e Shiu 2008), a entrada da China na OMC representou um passo significativo para o futuro desenvolvimento e reforma do setor. Como salientaram os autores, a China tornou-se o principal atuante e fornecedor dentro do segmento de TIC, que está em rápido crescimento no mundo. Ademais, em 2017, a China permaneceu como um dos principais mercados de telecomunicações no mundo, atendendo cerca de 201 milhões de clientes de telefonia fixa e 1,35 bilhão de linhas móveis China (2017).

A Tabela 1 aponta que, assim como na China, as telecomunicações brasileiras perderam participação na produção nacional (-0,47 p.p.), com participação de $1,74 \%$ em 2014. Essa perda de participação relativa do setor brasileiro também se verifica na composição da produção mundial do setor (-0,40p.p.), embora o setor tenha registrado um crescimento anual maior do que o do Japão (JPN), ou seja, uma expansão ao ano de quase $1,33 \%$ durante os dez anos analisados. Esses resultados podem ser reflexos dos avanços nacionais do setor. Em 2004, as telecomunicações apresentavam um total de 111,8 milhões de assinaturas em todos os seus serviços - telefonia (fixa e celular), internet (fixa e móvel) e TV por assinatura -, número que cresceu na ordem de 232\%, alcançando, em 2014, 372 milhões de assinaturas. Houve também um forte aumento na quantidade de prestadoras de serviços de telecomunicações. Em 2004, havia 293 empresas prestando serviços de banda larga fixa e 39 autorizações para a prestação de serviços telefônicos em todo país. Em 2014, esses números passaram para 4.879 empresas de banda larga e 198 autorizações Teleco (2014). Como tendência mundial, o setor brasileiro também passou por reformas estruturantes como a privatização e a mudança no grau de concorrência Chakraborty; Nandi (2011).

As telecomunicações das cinco economias desenvolvidas, reportadas na Tabela 1, ganharam participação na produção nacional, mas a maioria delas perdeu representatividade entre as produções regionais no mundo. Somente as telecomunicações 
da França (FRA) foi exceção. A economia francesa possui uma das maiores empresas de telefonia da Europa, a France Telecom (FT) SA, privatizada no ano de 1997. Essa companhia expandiu suas operações para além da fronteira europeia após a liberalização comercial no ano 2000. No entanto, a France Telecom (FT) SA passou a enfrentar concorrência com as empresas chinesas Nayak (2018 e Roulet (1988). Por outro lado, a economia japonesa (JPN) e a economia estadunidense (EUA) sofreram as maiores perdas com a participação regional, ou seja, uma variação negativa de $2,74 \%$ e $1,35 \%$, entre os anos de 2004 e 2014, respectivamente. Portanto, o crescimento das telecomunicações nesses dois países desenvolvidos não seguiu o ritmo global do setor, especialmente os observados na China, França e outros países (RoW). Contudo, essa queda de participação não se reflete em retração do setor em ambas as economias desenvolvidas (JPN e EUA), que obteve um crescimento anual em todo o período. A expansão anual das telecomunicações americanas somente perdeu para as chinesas e as francesas, que compõem empresas com operações ou participações no mercado europeu e asiático, especialmente. Entre os anos de 2004 e 2014, as telecomunicações americanas ganharam importância na produção nacional da economia dos Estados Unidos, ou seja, um incremento de 0,59 p.p. Esse crescimento na produção pode refletir o aumento na penetração dos serviços de telecomunicações, especialmente aqueles capazes de levar os serviços à distância, como os sem fio (e.g. telefonia e internet)USA (2016).

Mesmo com a evidência para uma mudança de descentralização regional na composição da oferta de telecomunicações no mundo, há dúvidas se o crescimento do setor esteve associado com ganhos de produtividade total, isto é, variações na PTF $(\boldsymbol{\tau})$, conforme a equação (11). A PTF ( $\boldsymbol{\tau})$ é um resultado líquido das variações de eficiência $\left(\boldsymbol{i}^{\prime} \Delta \boldsymbol{A}\right)$, que corresponde à mudança na relação técnica por insumos intermediários e, variação do valor adicionado $(\Delta v)$ que representa ganhos ou perdas na relação técnica por fatores primários. Ganhos de eficiência ou produtividade dos fatores de produção denotam menor gasto para esses dois componentes na estrutura de custos de telecomunicações por unidade de produção. A Figura 1 apresenta as variações percentuais acumuladas dos componentes da PTF $(\boldsymbol{\tau})$ do setor de telecomunicações em cada região mundial entre 2004 e 2014 . O painel (a) ilustra a decomposição $\operatorname{PTF}(\tau)$, enquanto o painel (b) exibe a decomposição de $\left(\boldsymbol{i}^{\prime} \Delta \boldsymbol{A}\right)$ por insumos intermediários domésticos (intra) e importados (inter) no processo produtivo do setor. Em geral, regiões situadas acima da linha de tendência na Figura 1 exibiram PTF $(\boldsymbol{\tau})$ positiva nos serviços de telecomunicações.

Mesmo com um forte crescimento anual, as telecomunicações chinesas exibiram uma queda da produtividade total dos fatores na ordem de $-0,48 \%$, cujo resultado se deve essencialmente pela perda da produtividade dos fatores primários $(-18,82 \%)$, que superou os ganhos de eficiência produtiva $\left(\boldsymbol{i}^{\prime} \Delta \boldsymbol{A}\right)$ no período. Esse padrão também se estende para os outros países do Mundo (RoW), em que a queda da PTF ( $\boldsymbol{\tau}$ ) de $-0,55 \%$ ocorreu principalmente pelo aumento no dispêndio do valor adicionado por unidade de produção $(\Delta v)$, algo em torno de $-7,58 \%$ entre os anos de 2004 e 2014. Em ambas as regiões, a eficiência produtiva ocorreu mais pelo uso de insumos intrarregionais (domésticos) que interregionais (importados), conforme observado na Figura (b). É oportuno destacar que os 
ganhos de participação regional na produção mundial das telecomunicações, nessas duas regiões, foram acompanhados com perdas de produtividade total ao longo dos 10 anos.

Figura 1: Variação Acumulada da Produtividade Total entre 2004 e 2014

(a) Decomposição da PTF

$\mathbf{i}^{\prime} \Delta \mathrm{A}(\%)$

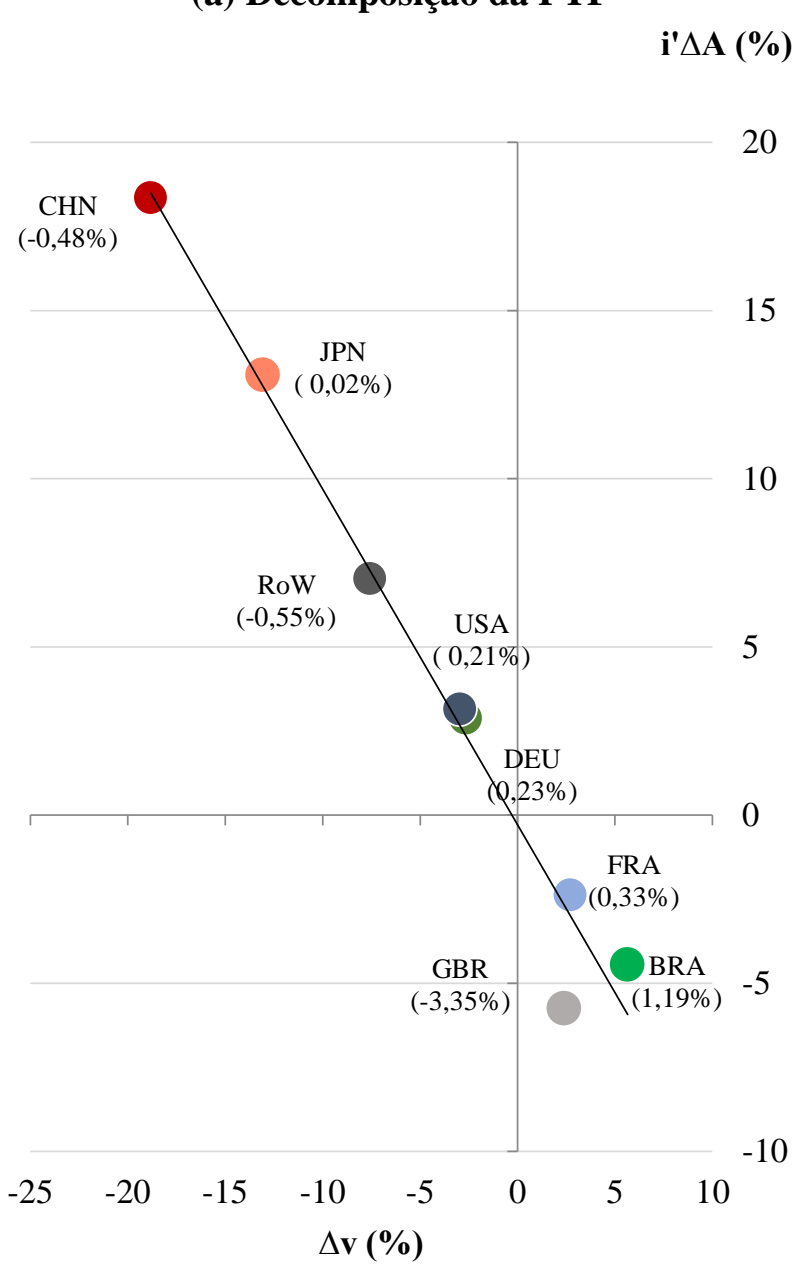

(b) Decomposição da i' $\Delta \mathrm{A}$

Fonte: Resultados da pesquisa.

Economias desenvolvidas como os Estados Unidos (USA), o Japão (JPN) e a Alemanha (DEU) integram o conjunto das regiões que também exibiram queda na produtividade dos fatores de produção $(\Delta v)$ no setor de telecomunicações. Contudo, diferente da China e Resto do Mundo, os ganhos de eficiência produtiva foram suficientes para alcançar uma variação positiva de $\operatorname{PTF}(\boldsymbol{\tau})$, mesmo que modestamente. Nas telecomunicações estadunidenses, os dispêndios de insumos intermediários importados 
cresceram em relação ao nível de produção $(-2,12 \%$, painel b), o que inibiu um ganho de eficiência técnica ainda maior. Ademais, entre as economias desenvolvidas, somente as telecomunicações francesas (FRA) e britânicas (GBR) exibiram ganhos de produtividade dos fatores primários $(\Delta \boldsymbol{v})$, porém com perdas de eficiência produtiva $\left(\boldsymbol{i}^{\prime} \boldsymbol{A} \boldsymbol{A}\right)$. Destacam-se as telecomunicações francesas (FRA) que, mesmo com a perda na relação técnica por insumos intermediários $\left(\boldsymbol{i}^{\prime} \boldsymbol{\Delta A}\right)$, alcançaram ganhos de produtividade total $(0,33 \%)$ durante o período. A perda de eficiência produtiva ocorreu majoritariamente pelo maior gasto de insumos intermediários importados por unidade de produção $(-1,96 \%$, painel b).

Em resumo, telecomunicações em economias desenvolvidas e/ou com maiores participações na composição da produção mundial do setor apresentaram ganhos de eficiência produtiva $\left(\boldsymbol{i}^{\prime} \Delta \boldsymbol{A}\right)$, mas também exibiram reduções na relação técnica por valor adicionado $(\Delta v)$. Essas telecomunicações regionais geralmente apresentam uma expressiva relação entre capital e trabalho no processo produtivo, o que gera maior dificuldade na redução do coeficiente técnico de valor adicionado $(\Delta v)$, quando há uma expansão da oferta dos serviços. Por essa razão, mesmo com ganhos de eficiência técnica, o efeito sobre a produtividade total do setor é pequeno. Ademais, as telecomunicações chinesas se tornaram a quarta maior do mundo, com maior quantidade de capital por trabalhador no setor, mas apresentando variações negativas de PTF, mesmo marginais.

A recíproca é também válida, ou seja, economias em desenvolvimento ou que apresentam uma menor composição global desse tipo de oferta de serviço tendem a exibir maiores ganhos de PTF $(\boldsymbol{\tau})$, cuja conclusão complementa a do estudo de Chakraborty e Nandi 2011). Os autores supracitados apontaram que nas economias em desenvolvimento as mudanças da PTF no setor são mais expressivas, explicadas pelo enfoque de "efeito alcance" da teoria de crescimento Solow (1957). Nessa variante, as telecomunicações brasileiras apresentaram relativamente a menor participação na produção mundial, mas ao mesmo tempo elas alcançaram a maior variação positiva PTF $(\boldsymbol{\tau})$, ou seja, acumulou um crescimento de 1,19\% entre 2004 e 2014. Esse ganho expressivo é melhor justificado pelo aumento de produtividade dos fatores primários $(5,65 \%)$ contra uma perda de eficiência produtiva $(-4,46 \%)$ no setor. A política de privatização e de investimentos não somente expandiu a oferta de telecomunicações na economia brasileira, mas permitiu que essa atividade setorial alcançasse ganhos de produtividade total. Entre os anos de 2004 e 2014, por exemplo, os investimentos cresceram $121 \%$, passando de $\mathrm{R} \$ 14,3$ bilhões para $\mathrm{R} \$ 31,7$ bilhões Teleco (2014). Conforme Lam e Shiu 2010), economias menos desenvolvidas onde o setor de telecomunicações é privatizado e opera em plena competição tendem a gerar maiores efeitos sobre o crescimento da economia e da PTF.

Entretanto, as evidências empíricas, como em Chakraborty e Nandi 2011), não mapearam quais os impactos dos coeficientes técnicos dos setores produtivos sobre a demanda de atividades de telecomunicações, especialmente em um mundo crescentemente globalizado e integrado com mudanças nos padrões de comércio e produção. Esses impactos advêm de canais intersetoriais e inter-regionais de cada sistema econômico regional. Dessa maneira, o presente estudo aplica o método de campo de influência, que reconhece os principais canais de transmissão dos efeitos diretos e indiretos para um 
pequeno choque nos coeficientes técnicos de produção. É possível avaliar as influências intersetoriais sobre as telecomunicações entre os anos de 2004 e 2014. O campo de influência reconhece os principais canais de transmissão dos efeitos diretos e indiretos por um pequeno choque nos coeficientes técnicos de produção. A estratégia é apresentar incialmente as principais influências intersetoriais por telecomunicações em cada país para o ano de 2004, tanto intra quanto interregionalmente. Posteriormente, é realizada uma comparação entre os resultados do campo de influência de 2014 com o ano de 2004.

A Figura 2 ilustra os resultados do campo de influência das telecomunicações para o ano de 2014. Cada resultado dentro das tabelas (bloco) representa uma interação, sendo as mais relevantes destacadas em uma escala de tons de cinza, indicando campos de influência acima da média - elos de interação fortes. Pela perspectiva do número de interações é possível visualizar que cada um dos setores possui uma relação com as telecomunicações, independentemente da região, encontra-se um total de 64 interações. Desse ponto de vista, a atividade da indústria de transformação (S3) interage acima da média em $100 \%$ das vezes, influenciando as telecomunicações em todas as regiões. Essa forte influência está em consonância com a Quarta Revolução Industrial Frank et al. (2019). Neste contexto, as indústrias de transformação demandam muito os serviços de telecomunicação a fim de criarem sistemas altamente interconectados, objetivando a descentralização e automação em busca de maior competitividade e produtividade na produção.

Outro setor que exerce forte influência sobre as telecomunicações é o setor de Eletricidade, gás, água, esgoto e reciclagem (S4). Conclui-se, portanto, que levar os mais diversos serviços de comunicação que proporcionam conversas instantâneas, streaming de músicas e vídeos, serviços de cloud computing e outras facilidades que rodeiam o mundo conectado demandam muita energia. Andrae e Edler 2015) salientam que, em 2012, aproximadamente $4,7 \%$ de toda a energia produzida mundialmente era utilizada para consumo de serviços de telecomunicações. Este trabalho prevê que, no ano de 2020, a parcela do uso global de energia para comunicação poderá estar entre $6 \%$ e $21 \%$. Os campos de influência também revelam, por outro lado, que os setores produtivos da França (FRA) e Reino Unido (GBR) interagem de maneira mais influente com o setor de telecomunicações de seus respectivos países se comparado às demais economias. Ao analisar as 112 interações, esses dois países e seus setores interagem acima da média com as telecomunicações em 50 delas. Em seguida, nesse mesmo ranking, encontra-se a Alemanha (DEU), que apresenta 42 setores de sua economia interagindo acima da média com a telecomunicação alemã.

Dentre os países europeus em estudo - Alemanha (DEU), França (FRA) e Reino Unido (GBR) - nota-se fortes interações dos setores intermediação financeira (S10) e Atividades profissionais e técnicas (S11) com o setor de telecomunicações. De acordo com dados da Organização para a Cooperação e Desenvolvimento Econômico (OCDE), no ano de 2010, pouco mais de $95 \%$ de todos os negócios de intermediação financeira desses três países já possuíam algum tipo de conexão à internet OCDE (2017). Para o mesmo período, a utilização de web sites dentro dessa categoria se vigorava em $99 \%$ dos negócios na 
Alemanha, 73\% na França e 91\% do Reino Unido. Quanto às atividades profissionais e técnicas (S11) para o ano de 2014, cerca de 98\% dos seus negócios nesses três países utilizavam algum tipo de conexão à internet. Para o mesmo período e categoria, $90 \%$ dos seus negócios na Alemanha e Reino Unido e 75\% na França utilizavam de web sites.

Figura 2: Influência das Telecomunicações sob a Ótica das Vendas (2014)

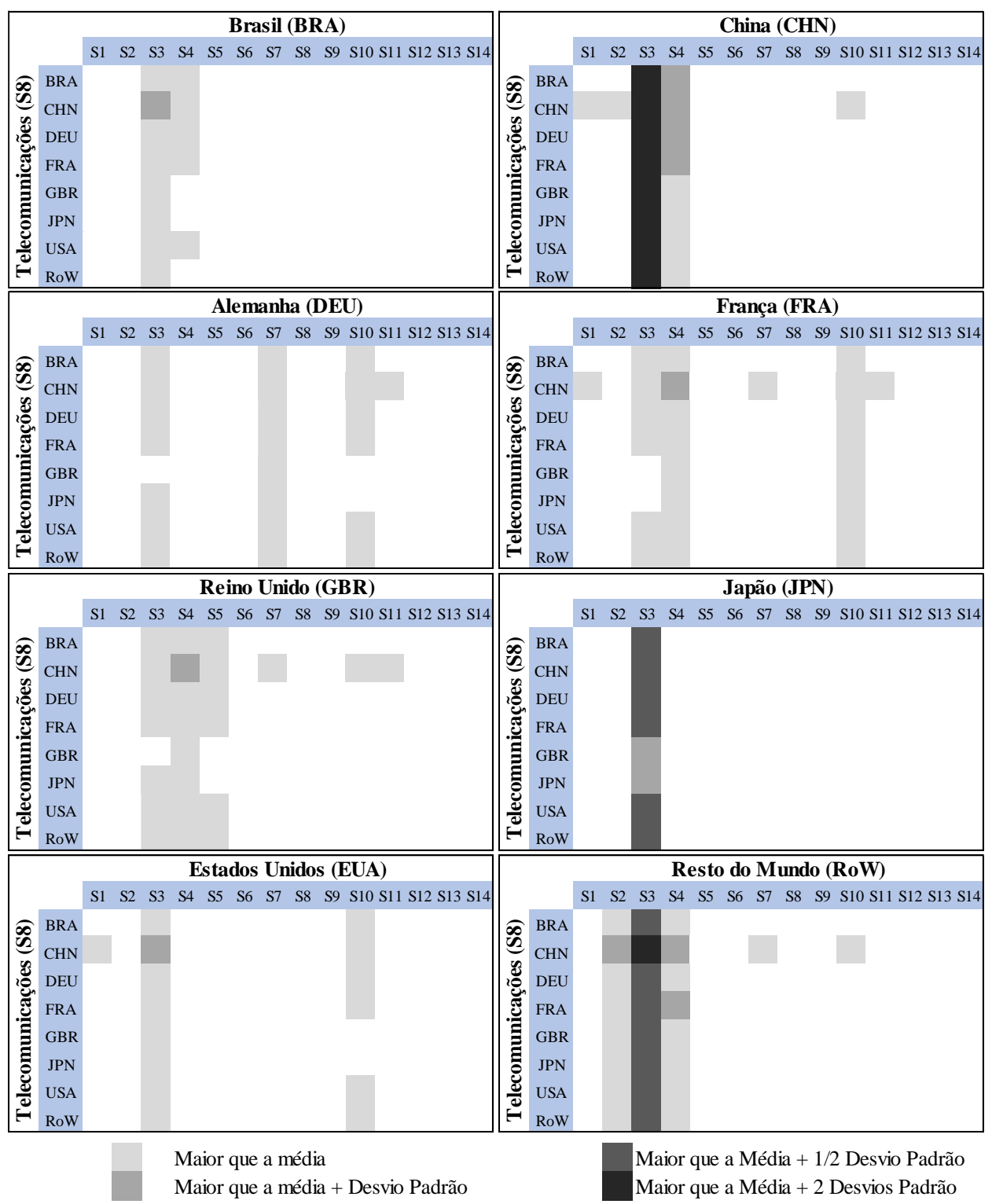

Fonte: Resultados da pesquisa. 
No Brasil, a atividade da indústria de transformação (S3) exerce maior influência nas telecomunicações do País, seguida por eletricidade, gás, água, esgoto e reciclagem (S4) intermediação financeira (S10) e atividades de correios e transporte (S7). O emprego das telecomunicações no setor de transporte tem elevado o seu potencial na medida em que as tecnologias móveis se tornam cada vez mais presentes. Essa transformação está sendo capaz de levar o transporte para uma nova geração de sistemas unificados, capaz de prover informações em tempo real, proporcionando práticas mais eficientes e rápidas que favorecem a todos World Bank (2016). Além disso, segundo uma pesquisa da Federação Brasileira de Bancos, entre os anos 2011 a 2015, houve um crescimento de mais de 100 vezes no número de transações feitas por Mobile Banking no Brasil, suportadas pelas operações de serviços de telecomunicações. A confiança do consumidor ao utilizar os canais digitais é reforçada pela segurança e praticidade oferecidas pela tecnologia, aliadas ao maior acesso da população à internet e ao uso crescente de smartphones FEBRABAN (2015).

Ao se comparar as médias da evolução da eficiência e PTF com a influência dos setores sobre as telecomunicações, tem-se um resultado análogo. Enquanto, em média, a eficiência produtiva e produtividade dos fatores primários das telecomunicações diminuíram em todo o mundo, pode-se constatar um aumento médio de $13 \%$ na influência de todos os setores sobre as telecomunicações. Como apontam Colecchia e Schreyer 2002) e Inklaar e Timmer 2007), empresas de setores de alta tecnologia e de negócios tornaramse mais dependentes dos serviços de telecomunicações perante a internacionalização da produção e consumo em todo o mundo.

\section{Considerações Finais}

Além da crescente globalização produtiva, o surgimento de novas tecnologias, a liberalização de comércio e a privatização do setor de telecomunicações durante os anos de 1990 influenciam as relações de consumo e produção em diversos sistemas produtivos no mundo. A oferta de serviços de telecomunicações expandiu rapidamente em muitas regiões econômicas, não somente nas principais produtoras regionais, beneficiando os setores industriais, de informação como e de serviços de negócios. Nesse contexto, este artigo ofereceu contribuições ao propor uma análise comparativa das mudanças de produtividade dos fatores de produção e da eficiência produtiva das telecomunicações nas principais economias regionais em um intervalo temporal de 10 anos.

Aplicando a técnica de decomposição da PTF, em um modelo de insumo-produto que reconhece os canais multilaterais das economias internacionais (WIO), foi possível constatar as perdas e ganhos de eficiência dessa atividade na utilização de insumos intermediários, bem como de onde eles se originaram, além dos ganhos dos fatores de produção individualmente para cada país. Em seguida, essa análise estática foi articulada com uma avaliação estrutural das interações intersetoriais mais influentes sobre as telecomunicações em uma perspectiva intrarregional. A ideia foi averiguar a mudança no 
padrão de produção e comércio que mais diretamente se relaciona com as atividades de telecomunicações. Nessa etapa da pesquisa fez-se o uso da técnica de campo de influência, que permitiu observar as variações das influências intersetoriais entre os anos de $2004 \mathrm{e}$ 2014, que os setores produtivos exerciam sobre a demanda de telecomunicações em todo o mundo.

Em termos reais, o setor de telecomunicação cresceu $45,62 \%$ em valor bruto de produção entre os anos de 2004 e 2014. Nesse mesmo período, o conjunto das sete economias que mais produziam esses serviços perderam 3,43\% de participação para as outras regiões do mundo, com destaque para a maior perda de participação dos Estados Unidos e maior ganho da China. Essas duas economias mundiais passaram a produzir quase $38 \%$ de telecomunicações em todo o mundo. Em média, a perda em eficiência dessa atividade na utilização de insumos intermediários foi maior que os ganhos em produtividade dos fatores de produção em todo o mundo. Nesse caso, o setor de telecomunicações perdeu em PTF dentro desse intervalo de 10 anos. De forma individualizada, o setor de telecomunicações da China, Reino Unido e o Resto do Mundo destacaram-se como os únicos a sofrerem perdas de produtividade total na análise. $\mathrm{Na}$ China e nos demais países no mundo (RoW), a queda é justificada pela perda de eficiência produtiva, ao passo que no Reino Unido se deve pela queda de produtividade dos fatores de produção.

Por outro lado, as demais economias desenvolvidas e com destaque na distribuição regional na oferta de telecomunicações exibiram PTFs positivas, muito por conta do ganho de eficiência produtiva ao longo dos dez anos. Nessas economias desenvolvidas, a atividade de telecomunicações geralmente apresenta uma quantidade de capital por trabalhador elevada, o que torna o efeito sobre a produtividade ainda mais marginal. Já as telecomunicações brasileiras se destacam por apresentarem os maiores ganhos de produtividade total, mesmo com perda de eficiência produtiva. É um setor que cresceu moderadamente entre os anos de 2004 e 2014, cuja razão capital-trabalho é baixa. Nos resultados brasileiros há, portanto, certo "efeito alcance" das tradicionais teorias de crescimento Solow (1957), de maneira que os efeitos sobre a PTF parecem maiores as políticas de investimento e de privatização. Como a China, o Brasil parece ter aproveitado da vantagem de países com tecnologia retardatária nos anos 1990, como sugerem Lam e Shiu 2010).

Por seu turno, o campo de influência mostrou os setores que mais interagem com as telecomunicações em todo o mundo. Essa análise levou em conta os principais canais de transmissão dos efeitos diretos e indiretos de cada relação técnica de produção por sistema econômico (região). Um dos setores produtivos em destaque foi a indústria de transformação, que influenciou acima da média em $100 \%$ das vezes. As atividades de "eletricidade, gás, água, esgoto e reciclagem", "atividades financeiras" e "atividades de transporte e correios" também se sobressaíram por serem grandes demandantes dos serviços de telecomunicações e por apresentarem fortes interações acima da média com o setor na maioria das economias. Relacionando-se a evolução da eficiência e produtividade das telecomunicações com a evolução da eficiência e influência dos setores produtivos 
sobre as telecomunicações, em geral, os países que apresentam ganhos de eficiência total e PTF em suas telecomunicações obtiveram uma queda na influência dos seus setores sobre essas teles. Esta relação é esperada, uma vez que a partir da evolução positiva desses fatores os serviços prestados podem fornecer menor pressão no processo produtivo dos seus demandantes. Dessa maneira, esta pesquisa buscou contribuir com o acompanhamento da evolução da produtividade do setor de telecomunicações, além de apresentar uma análise intersetorial, intra e interregional que permitiu identificar quais os setores que mais o demandam entre os anos 2004 a 2014, nas regiões selecionadas. Contudo, existem limitações. Em primeiro lugar, a inexistência de uma base de dados mais recente, posterior ao ano de 2014. Outra limitação parte da delimitação de países ser a única disponível, o que impede que a mesma análise seja aplicada além das regiões mapeadas pela WIOD. A base de dados também não permite que as telecomunicações sejam desagregadas de acordo com o tipo de serviço demandado.

Os resultados obtidos também podem ser úteis tanto aos gestores de políticas públicas quanto aos tomadores de decisões das empresas de telecomunicações. Uma vez que o estudo identificou os setores que mais interagem com as telecomunicações, ou seja, quais são mais intensivos no uso de seus serviços, é possível saber de antemão quais atividades sofrerão com alterações das políticas aplicadas ao setor. As informações sobre aumento e perda de eficiência e de produtividade podem ser utilizadas também na formulação de soluções que estimulem melhores resultados na busca de um setor mais produtivo em benefício de todos os seus usuários.

\section{Agradecimentos}

Os autores agradecem à Fundação de Amparo à Pesquisa do Estado de Minas Gerais (Fapemig), à Coordenação de Aperfeiçoamento de Pessoal de Nível Superior (Capes) e ao Conselho Nacional de Desenvolvimento Científico e Tecnológico (CNPq) pelo apoio financeiro. 


\section{Referências}

ABI RESEARCH. Global Pay TV Subscriber Base to Surpass 1.1 Billion in 2020. Disponível em: <https://www.abiresearch.com/press/global-pay-tv-subscriber-base-tosurpass-11-billio/>. Acesso em: 18/6/2017.

ANDRAE, A.; EDLER, T. On Global Electricity Usage of Communication Technology: Trends to 2030. Challenges, v. 6, n. 1, 2015.DOI: https://doi.org/10.3390/challe6010117

ARTO, I.; DIETZENBACHER, E. Drivers of the growth in global greenhouse gas emissions. Environmental Science and Technology, v. 48, n. 10, p. 5388-5394, 2014. DOI: https://doi.org/10.1021/es5005347

ASCHAUER, D. A. Is public expenditure productive? Journal of Monetary Economics, v. 23, n. 2, p. 177-200, 1989.DOI: https://doi.org/10.1016/0304-3932(89)90047-0

CHAKRABORTY, C.; NANDI, B. "Mainline" telecommunications infrastructure, levels of development and economic growth: Evidence from a panel of developing countries.

Telecommunications Policy, v. 35, n. 5, p. 441-449, 2011.

DOI: https://doi.org/10.1016/j.telpol.2011.03.004

CHINA. Assinantes de telefone em abril de 2017. Pequim: MII - Ministry of industry and Information Technology of the People's Republic of China, 2017. Disponível em: http://www.miit.gov.cn/newweb/n1146312/n1146904/n1648372/c5653375/content.html

COLECCHIA, A.; SCHREYER, P. ICT investment and economic growth in the 1990s: Is the United States a unique case? Review of Economic Dynamics, v. 5, n. 2, p. 408-442, 2002. DOI: https://doi.org/10.1006/redy.2002.0170

COUNCIL, N. R. Renewing US Telecommunications Research. Washington, United States: National Academies Press, 2006.

CRONIN, F. J.; COLLERAN, E. K.; HERBERT, P. L.; LEWITZKY, S.

Telecommunications and growth. The contribution of telecommunications infrastructure investment to aggregate and sectoral productivity. Telecommunications Policy, v. 17, $\mathrm{n}$. 9, p. 677-690, 1993. DOI: https://doi.org/10.1016/0308-5961(93)90039-6

DATTA, P.; MBARIKA, V. W. A global investigation of granger causality between information infrastructure investment and service-sector growth. Information Society, v. 22, n. 3, p. 149-163, 2006. DOI: https://doi.org/10.1080/01972240600677847

DIETZENBACHER, E.; LOS, B.; STEHRER, R.; TIMMER, M.; DE VRIES, G. The construction of world input-output tables in the WIOD project. Economic Systems Research, v. 25, n. 1, p. 71-98, 2013.

DOI :https://doi.org/10.1080/09535314.2012.761180

FEBRABAN. Pesquisa FEBRABAN de Tecnologia Bancária 2015. Brasília:

Federação Brasileira de Bancos (FEBRABAN), 2015. Disponível em: 
https://cmsportal.febraban.org.br/Arquivos/documentos/PDF/Relatorio - Pesquisa FEBRABAN de Tecnologia Bancária 2015.pdf

FRANK, A. G.; DALENOGARE, L. S.; AYALA, N. F. Industry 4.0 technologies: Implementation patterns in manufacturing companies. International Journal of Production Economics, v. 210, p. 15-26, 2019. DOI: https://doi.org/10.1016/j.ijpe.2019.01.004

GSMA INTELLIGENCE. The Mobile Economy. London, United Kingdom: GSM Association, 2017. https://doi.org/10.3390/molecules14010298

HEBER, F.; FISCHER, T. Regulação do Estado e reformas nas telecomunicações. Rev. adm. pública, v. 34, n. 5, p. 143-163, 1997. Disponível em: <http://bibliotecadigital.fgv.br/ojs/index.php/rap/article/view/6310/4900>. .

HIRSCHMAN, A. O.; SCHLAEFFER, L. Estratégia do desenvolvimento econômico: The strategy of economic development. 1958. Fundo de cultura, 1960.

HONG, J. P.; BYUN, J. E.; KIM, P. R. Structural changes and growth factors of the ICT industry in Korea: 1995-2009. Telecommunications Policy, v. 40, n. 5, p. 502-513, 2016. DOI: https://doi.org/10.1016/j.telpol.2015.08.001

INKLAAR, R.; TIMMER, M. P. International comparisons of industry output, inputs and productivity levels: Methodology and new results. Economic Systems Research, 2007. DOI: https://doi.org/10.1080/09535310701572040

INTERNATIONAL TELECOMMUNICATION UNION. Measuring the Information Society Report 2017- Volume 1. 2017. DOI: https://doi.org/10.3359/oz0303157

JUNG, H. J.; NA, K. Y.; YOON, C. H. The role of ICT in Korea's economic growth: Productivity changes across industries since the 1990s. Telecommunications Policy, v. 37, n. 4-5, p. 292-310, 2013. DOI: https://doi.org/10.1016/j.telpol.2012.06.006

KOSZEREK, D.; HAVIK, K.; MORROW, K. M.; ROGER, W.; SCHONBORN, F. An overview of the EU KLEMS Growth and Productivity Accounts. Brussels, Belgium: Directorate General Economic and Financial Affairs (DG ECFIN), European Commission, 2007. Disponível em: https://ec.europa.eu/economy_finance/publications/pages/publication9467_en.pdf LAM, P. L.; SHIU, A. Productivity analysis of the telecommunications sector in China. Telecommunications Policy, v. 32, n. 8, p. 559-571, 2008.

DOI: https://doi.org/10.1016/j.telpol.2008.06.004

LAM, P. L.; SHIU, A. Economic growth, telecommunications development and productivity growth of the telecommunications sector: Evidence around the world. Telecommunications Policy, v. 34, n. 4, p. 185-199, 2010.

DOI: https://doi.org/10.1016/j.telpol.2009.12.001 
LATIF, Z.; MENGKE, Y.; DANISH; et al. The dynamics of ICT, foreign direct investment, globalization and economic growth: Panel estimation robust to heterogeneity and cross-sectional dependence. Telematics and Informatics, v. 35, n. 2, p. 318-328, 2018. DOI: https://doi.org/10.1016/j.tele.2017.12.006

LI, W.; XU, L. C. The political economy of privatization and competition: Cross-country evidence from the telecommunications sector. Journal of Comparative Economics, 2002. DOI: https://doi.org/10.1006/jcec.2002.1791

MILLER, R. E.; BLAIR, P. D. Input - Output Analysis: Foundations and Extensions. Cambridge: Cambridge University Press, 2009.

DOI: https://doi.org/10.1017/CBO9780511626982

NAYAK, A. Internationalisation of the Indian telecommunication industry (1947-2004): A firm-level perspective. Business History, p. 1-20, 2018. Routledge. DOI: https://doi.org/10.1080/00076791.2018.1492553

NIEBEL, T. ICT and economic growth - Comparing developing, emerging and developed countries. World Development, v. 104, p. 197-211, 2018.

DOI: https://doi.org/10.1016/j.worlddev.2017.11.024

OCDE. OECD Data. Disponível em: <https://stats.oecd.org/>. Acesso em: 8/8/2016.

PERROUX, F. A Economia do Século XX - Os espaços economicos. Porto: Herder, 1967.

PRADHAN, R. P.; ARVIN, M. B.; NAIR, M.; MITTAL, J.; NORMAN, N. R.

Telecommunications infrastructure and usage and the FDI-growth nexus: evidence from Asian-21 countries. Information Technology for Development, v. 23, n. 2, p. 235-260, 2017. DOI: https://doi.org/10.1080/02681102.2016.1217822

ROHMAN, I. K. The globalization and stagnation of the ICT sectors in European countries: An input-output analysis. Telecommunications Policy, v. 37, n. 4-5, p. 387399, 2013. DOI: https://doi.org/10.1016/j.telpol.2012.05.001

ROHMAN, I. K.; BOHLIN, E. Decomposition analysis of the telecommunications sector in Indonesia: What does the cellular era shed light on? Telecommunications Policy, v. 38, n. 3, p. 248-263, 2014. DOI: https://doi.org/10.1016/j.telpol.2013.10.006

ROS, A. J.; BANERJEE, A. Telecommunications privatization and tariff rebalancing: Evidence from Latin America. Telecommunications Policy, v. 24, n. 3, 2000. DOI: https://doi.org/10.1016/S0308-5961(00)00013-6

ROULET, M. France telecom. Telecommunications Policy, v. 12, n. 2, 1988. DOI: https://doi.org/10.1016/0308-5961(88)90002-x 
SILVA, G. D. DA; PEROBELLI, F. S. Interconexões Setoriais e PIB per capita: há relação direta entre ambas as variáveis? Estudos Econômicos (São Paulo), v. 48, n. 2, p. 251-282, 2018. SciELO Brasil.

SOLOW, R. M. Technical Change and the Aggregate Production Function. The Review of Economics and Statistics, p. 312-320, 1957.

DOI: https://doi.org/10.1021/acs.inorgchem.7b02551

SONIS, M.; HEWINGS, G. J. D. Error and sensitivity input-output analysis: a new approach. Frontiers of Input-output Analysis, p. 232-244, 1989. Nueva York, Oxford.

SONIS, M.; HEWINGS, G. J. D. Economic landscapes: Multiplier product matrix analysis for multiregional input-output systems. Hitotsubashi Journal of Economics, v. 40, n. 1, p. 59-74, 1999. Disponível em:

<http://www.scopus.com/inward/record.url?eid=2-s2.0-

0033445155\&partnerID $=40 \& m d 5=2364 d 997 f 0763073 a 04 d a 4 a 00 f 356445>$. .

SRIDHAR, K. S.; SRIDHAR, V. Telecommunications infrastructure and economic growth : evidence from developing countries. Applied Econometrics and International Development, v. 7, n. 2, 2009. DOI: https://doi.org/10.1016/0308-5961(91)90007-X

TELECO, B. O desempenho do setor de telecomunicações no Brasil em 2014: Séries temporais, preparado pelo teleco para a Telebrasil. , 2014. Brasília: Teleco.

UNITED NATIONS. International Standarf Industrial Classification of All Economic Activities (ISIC). Statistical Papers, 2008.

DOI: https://doi.org/10.1007/s13398-014-0173-7.2

USA. International Telecommunications Traffic and Revenue Data Report (2014).

Washington, D.C: FCC - Federal Communications Commission, 2016.

WERTHEIN, J. A sociedade da informação e seus desafios. Ciência da Informação, v. 29, n. 2, p. 71-77, 2000. DOI: https://doi.org/10.1590/S0100-19652000000200009

WORLD BANK. Digital transformations - Digital divides. In World development report 2016: Digital dividends, 2016. Washington DC, USA: World Bank.

DOI: https://doi.org/10.1596/978-1-4648-0671-1

WORLD BANK GROUP. World Development Report 2016: Digital Dividends.

Washington, D.C: World Bank Publications/ International Bank for Reconstruction and Development / The World Bank, 2016.

YU, L.; SUOJAPELTO, K.; HALLIKAS, J.; TANG, O. Chinese ICT industry from supply chain perspective - A case study of the major Chinese ICT players. International Journal of Production Economics, v. 115, n. 2, p. 374-387, 2008.

DOI: https://doi.org/10.1016/j.ijpe.2008.03.011 